\title{
Estimating the Household Consumption Function in Saudi Arabia
}

Goblan Al Gahtani, Carlo Andrea Bollino, Simona Bigerna and Axel Pierru 


\section{About KAPSARC}

The King Abdullah Petroleum Studies and Research Center (KAPSARC) is a non-profit global institution dedicated to independent research into energy economics, policy, technology and the environment across all types of energy. KAPSARC's mandate is to advance the understanding of energy challenges and opportunities facing the world today and tomorrow, through unbiased, independent, and high-caliber research for the benefit of society. KAPSARC is located in Riyadh, Saudi Arabia.

\section{Legal Notice}

(C) Copyright 2019 King Abdullah Petroleum Studies and Research Center (KAPSARC). No portion of this document may be reproduced or utilized without the proper attribution to KAPSARC. 


\section{Key Points}

his research is part of a joint project between the Saudi Arabian Monetary Authority (SAMA) and the

King Abdullah Petroleum Studies and Research Center (KAPSARC).

This paper estimates a micro-based life cycle consumption model for Saudi Arabia over the period 1970-2017.

The estimate of consumption behavior in this paper is identified as centering on the income effect and the wealth effect:

The income effect is defined as the direct impact on consumption of a variation in income.

The wealth effect is defined as a consumer's perception of a change in his or her wealth and a concomitant decision either to liquidate some of that wealth to enable an increase in consumption (in the case of a positive wealth change) or to decrease consumption in order to restore the consumer's desired level of wealth (in the case of a negative wealth change).

The wealth effect on consumption can be substantially different from the income effect because it is more closely related to consumers' expectations of, and fluctuations in, the value of real and financial assets.

The authors' estimation shows that both income and wealth have significant effects on household consumption in Saudi Arabia, with a long-run marginal propensity to consume (MPC) out of income of around 0.73-0.95 and out of wealth of around 0.06.

The sensitivity of consumption to income and wealth in Saudi Arabia appears to be consistent with the growth of the Saudi economy. 


\section{Summary}

E conomic growth in Saudi Arabia has experienced a new phase of variability in the last five years, in part due to its increased integration into the international economy, which, in turn, has been hit by policy shocks and turbulence.

The Saudi Arabian government's recent policy strategies, such as energy price reforms, the introduction of a $5 \%$ value added tax (VAT) at the start of 2018 and a new fiscal stimulus package are included in our assessment of the Kingdom's aggregate consumption behavior.

A detailed analysis of national consumption patterns can be of great use to a given country's monetary authority and/or policymakers, as household consumption growth helps fuel economic growth and domestic savings contribute to national investment growth.

Analysis of the macro consumption function can help policymakers focus on the macroeconomic compatibility of aggregate savings and consumption patterns when formulating an economic policy to support the growth rate of the economy.

The authors' estimation shows that both income and wealth have significant effects on private consumption behavior.
The short-run response of consumption to changes in income is estimated in the range 0.13-0.41. In the long run, the values are around 0.73-0.95.

The immediate price effect ranges from -0.33 to -0.49 .

The average estimated values imply that in 2018 an income shock of 100 Saudi riyals will generate an additional consumption of 13 in the first year, 50 after about 1.3 years, and a long-run effect of 95 Saudi riyals.

The short-run response of consumption to changes in wealth is slightly negative because expectations of an increase in volatility may induce a precautionary household behavior to increase saving, i.e., lower consumption.

The long-run wealth effect is around 0.06, which is consistent with this interpretation. In this context, 0.06 means that a long-run wealth increase of 100 Saudi riyals determines an additional 6 Saudi riyals increase in consumption.

Based on the estimated function, a simulation for the year 2018 of the additional effect of VAT on Saudi household consumption shows that the introduction of VAT can be estimated as a one-time $-0.3 \%$ impact on consumption. 


\section{Introduction}

conomic growth in Saudi Arabia has experienced a new phase of variability in the last five years, with more pronounced acceleration and slowdown, within the context of its increasing integration into the international economy. This phase has been characterized by different patterns of and changes in economic growth and policy stances in the advanced economies, the financial markets and energy markets.

There have been several important economic policy changes in the Kingdom, such as energy price reforms, the introduction of a value added tax (VAT) in 2018 and a new fiscal stimulus package.

In the context of macroeconomic analysis, one crucial behavioral variable that is sensitive to fiscal policy is the aggregate consumption function. The design of an appropriate national fiscal policy requires understanding private consumption patterns. This is also of interest for the monetary authorities because consumption growth is at the root of real growth and saving is at the root of investment growth. In addition, very rapid economic growth can contribute to inflationary pressures. Given that the ultimate goal of most countries' economic policies is to spur economic growth and the population's general welfare, an accurate and robust estimation of consumption behavior should be a helpful, perhaps even an essential, tool for policymakers.

This paper aims to make a new contribution to the existing literature, estimating a fully micro-founded life cycle consumption model for Saudi Arabia for the period 1970-2017, using official data for consumption, disposable income, interest rates, and real and financial wealth.

The analysis of the macro consumption function has two lines of interest: i) macroeconomic compatibility of aggregate savings and consumption patterns, with the objectives of an economic growth policy, and ii) individual intertemporal behavior in the life cycle framework, including institutional analysis of market imperfections, liquidity constraints, and asymmetric information.

The general results in the literature (Kaplan and Violante 2010) are based on the crucial distinction between the short-term and the long-term effects of income shocks. It is also possible to make a distinction between permanent and transitory income shocks and to take into account the possibility for consumers to borrow or not borrow. In the latter case, borrowing helps smooth income fluctuation and therefore lowers the immediate income effect.

In addition, the empirical analysis of consumption behavior has separately estimated income effects and wealth effects following a long tradition in the literature. The income effect is the direct impact on consumption of a variation in income. The wealth effect is the response of consumption when the consumer perceives a change in his wealth and decides to liquidate a part of it to increase consumption (in the case of a positive change in wealth) or to decrease consumption to restore the desired level of wealth (in the case of a negative change in wealth). The wealth effect on consumption can be substantially different from the income effect because it is more related to consumers' perceptions of expectations and fluctuations of the value of real and financial assets and can vary across different economies. Studies for advanced economies have highlighted that the wealth effect is lower in the Euro area than in the United States (U.S.) (Slacalek 2009; Sousa 2008; Sousa 2009). Moreover, consumption is characterized by persistent responses to shocks, which implies that the long-run effect of wealth is significantly larger than its short-run effect. We take 


\section{Introduction}

into account studies in the macro empirical literature, which typically use aggregate time series variables, to specify a dynamic representation of short-term adjustments and a long-term structural relation using an error correction model (ECM) representation. The typical empirical results, with realistic assumptions about the parameters of interest (such as the time horizon, the intertemporal discount rate, and the age distribution of the population), show differences between advanced and emerging countries (Peltonen et al. 2011) and between two types of consumers: those who can freely borrow and those who are unable to borrow (for whatever reason). The former are more able to smooth and adapt their behavior to sudden shocks, while the latter are forced by sudden shocks to adapt their consumption behavior (Attanasio and Pistaferri 2016).
A significant body of literature (as discussed in Jappelli and Pistaferri 2010) analyzing developed economies shows a marginal propensity to consume (MPC) ranging between 0.5 and 0.9 . These estimations take into account predictable and unpredictable income changes, precautionary savings, credit, and insurance market instruments available to consumers. So far, scarce attention has been devoted to the determinants of such aggregate patterns in rapid growth emerging economies.

The rest of the paper is organized as follows: Section 2 surveys the existing literature, Section 3 provides a review of the data and methodology and Section 4 summarizes the empirical results. Section 5 concludes the paper. 


\section{What We Learn From the Literature}

everal well-known hypotheses were established by influential economists starting in the 1930s. Keynes (1936) was the first to formulate a consumption function, creating the absolute income hypothesis $(\mathrm{AlH})$ which held that, if income increases, consumption will also increase proportionally but only by a fraction of the initial increase in current income. However, in the 1940s the findings of many empirical articles contrasted with the AlH. This led to more theoretical frameworks of consumption patterns, such as Duesenberry's (1949) relative income hypothesis $(\mathrm{RIH})$. Duesenberry differed from Keynes in asserting that current levels of consumption are further driven by levels of consumption reached in earlier periods.

Modigliani and Brumberg (1954) formulated the foundations of the life cycle hypothesis (LCH). This is the basis of the modern theory that explains aggregate consumption from a representation of individual behavior, assuming a specification of a multi-period utility maximization behavior. In this context, consumption depends on income, interest rate and the age of the agent. Friedman (1957) provided the permanent income hypothesis $(\mathrm{PIH})$ to account for empirical anomalies in the data for prior hypotheses. Later, Hall (1978) applied rational expectations to both the $\mathrm{LCH}$ and the $\mathrm{PIH}$. Several papers were then conducted to explore the consumption function for developed economies (Muellbauer 1994; Church et al. 1994; Hendry 1994; Muellbauer and Lattimore 1995; Fagan et al. 2005; Smets and Wouters 2003; Davis and Palumbo 2001; Rossi and Visco 1994).

The main lesson derived from the literature is that the general specification of consumption needs to involve a complex function of income as the main determinant. In this sense, the recent literature has overcome the simplistic Keynesian formulation of the linear consumption function, which linked current consumption to current income. In a realistic framework, individual consumers take into account not only current income but also an expectation of future income streams and an appropriate interest rate, which represents the consumer time preference for discounting future income. In addition, accumulated and expected wealth may influence current consumption-smoothing decisions. Consumption-smoothing also results from consumers' decisions to absorb short-term income fluctuations, which may yield an increase in savings to postpone current consumption or a decrease in savings to maintain current consumption levels at the expense of future consumption.

Although many papers have been written on the propensity of developed economies to consume out of income, less attention has been paid to developing economies. Research on Saudi Arabia is limited but includes Al-Bashir (1977) with data referring to the 1960s; Tawi (1984); Ibrahim (2014); and Algaeed (2016). Tawi estimated several specifications, from a simple Keynesian consumption function to a permanent income consumption function. The very low estimated marginal propensity to consume (MPC) $(0.40)$ is justified by the number of foreign workers who save a high proportion of their income, combined with the fact that many basic goods and health and education services are subsidized. These results are of limited use as the estimation is static. Ibrahim also finds a very low MPC of around 0.4 and Algaaed finds only monetary effects on consumption. Hasanov et al. (2018) estimate consumption in an annual macro model for Saudi Arabia from 1997-2015, estimating an MPC of around 0.7. In summary, the previous estimation of the MPC in Saudi Arabia is in the range 0.4-0.7.

We note that one implication of economic theory is that the MPC is higher in low-wealth countries (Carrol et al. 2014) and in emerging economies. 
Also, the MPC depends on the population age composition of the economy, as the LCH predicts lower MPCs in middle age, with higher consumption rates among young people. In this sense, the MPC in the Saudi economy, which has a young population and a per capita income level higher than most emerging economies, should be lower than that of advanced economies because the population of advanced economies is, on average, older than that of the Kingdom. The MPC in Saudi Arabia should be higher than in many emerging countries because incomes in emerging economies are, on average, lower than those in the Kingdom. In addition, Saudi consumers have taken a more cautious attitude toward the local Tadawul stock market after the 2007 crisis.

To the best of our knowledge, our proposed dynamic consumption function for Saudi Arabia, following the seminal work of Ando-Modigliani (1963), is the first attempt to examine the MPC using income in a fully theoretical life cycle dynamic. 


\section{Data and Methodology}

his paper presents an econometric analysis of a consumption function of Saudi Arabia, specifically founded on optimizing behavior. It refers to the household sector and is based on the traditional linear approximation of the AndoModigliani life cycle model. The data used are taken from Saudi Arabia's General Authority for Statistics (GaStat) and the Saudi Arabian Monetary
Authority's (SAMA's) yearly published statistics from 1970-2017 (data originally referencing the Hijri calendar was converted to the Gregorian calendar). We denote the real consumption with $c$, the rate of change of prices with $\pi$, real interest rate with $r$, real income with $y$, real wealth with $w$ and savings with $s=y-c$. 


\section{Data}

$\mathrm{T}$ he choice of the empirical variables is guided by the principle of using official data that are clearly identifiable and recoverable from the published statistics, as is common practice in macro-econometric models (e.g. Cicowiez and Lofgren 2017; Vitek 2018). We take the private final consumption expenditure, in 2010 prices, from the national accounts, defined as $c$. We take as income $y$ the non-oil gross domestic product (GDP) in 2010 prices (non-oil GDP is defined by subtracting oil extraction and oil refining from the total real GDP, excluding tariff revenue). We construct the wealth variable $w$ as the sum of financial wealth approximated by the broad money supply (M3) and the market capitalization of the Tadawul stock market, using published GaStat data. We have followed the methodology of constructing the financial wealth of the household sector used by the International Monetary Fund (IMF) (2006) and the European Central Bank (ECB) (2016).

Table 1 shows the most recent data of the sample used for estimation. From 2008 to 2014, the growth of Saudi non-oil GDP in real terms was relatively high (above 6\%); growth was lower between 20152017. The real private consumption growth rate has generally been higher than the GDP non-oil growth rate, with exceptions only in 2010, 2011 and 2013.

Figures 1 and 2 show the long term trend in consumption and income and the consumption/ income ratio. Note that in the last 20 years, real consumption and income increased three times. The big fluctuation of the consumption/income ratio in the 1970s is due to the sudden increase in non-oil GDP between 1974-75, which was followed by a sluggish increase in private consumption. The consumption/income ratio was more stable after 1982.

Consumption growth slowed from 2016 to 2017, following a fall in GDP. The combined result has been a slight increase in the consumption/income ratio since 2015 (see Appendix for a more detailed data description).

Table 1. Real private consumption and non-oil GDP in (million Saudi riyals) and growth rates (percent).

\begin{tabular}{|c|c|c|c|c|c|}
\hline Year & $\begin{array}{l}\text { Private } \\
\text { consumption }\end{array}$ & GDP non-oil & $\begin{array}{l}\text { Private consump- } \\
\text { tion growth rate }\end{array}$ & $\begin{array}{l}\text { GDP non-oil growth } \\
\text { rate }\end{array}$ & $\begin{array}{l}\text { Consumption/ } \\
\text { income ratio }\end{array}$ \\
\hline 2008 & 565269.2 & 934643.8 & 12.2 & 8.0 & 0.605 \\
\hline 2009 & 615666.2 & 989774.3 & 8.9 & 5.9 & 0.622 \\
\hline 2010 & 639417.4 & 1084288 & 3.9 & 9.5 & 0.59 \\
\hline 2011 & 650434.9 & 1173161 & 1.7 & 8.2 & 0.554 \\
\hline 2012 & 726340.4 & 1237790 & 11.7 & 5.5 & 0.587 \\
\hline 2013 & 749694.2 & 1317127 & 3.2 & 6.4 & 0.569 \\
\hline 2014 & 795672.7 & 1381172 & 6.1 & 4.9 & 0.576 \\
\hline 2015 & 849475.3 & 1425400 & 6.8 & 3.2 & 0.596 \\
\hline 2016 & 867790 & 1428629 & 2.2 & 0.2 & 0.607 \\
\hline 2017 & 884836.9 & 1443072 & 2.0 & 1.0 & 0.613 \\
\hline
\end{tabular}

Source: KAPSARC. 
Figure 1. Consumption and income (billion real Saudi riyals).

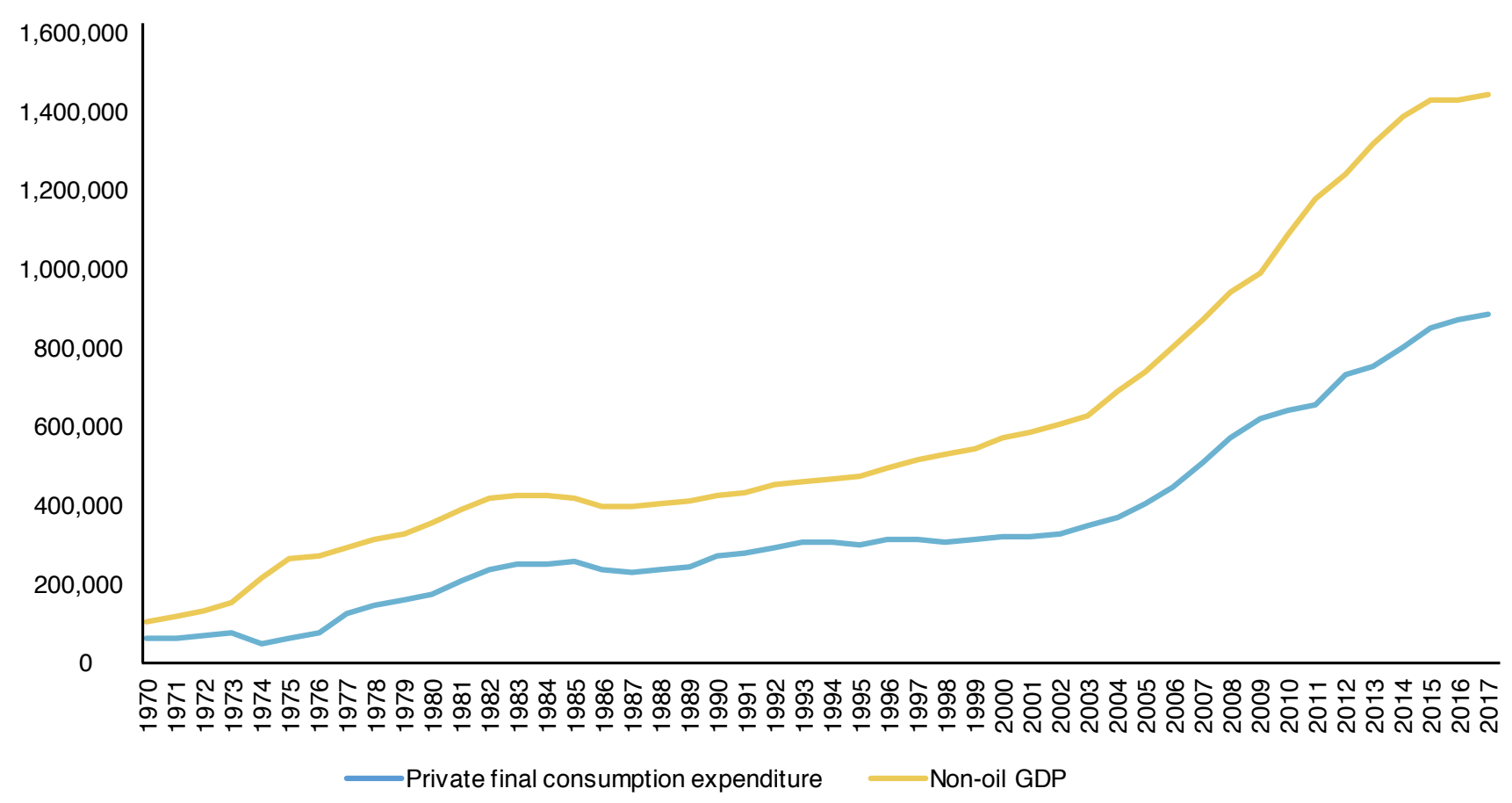

Source: KAPSARC analysis.

Figure 2. Consumption to income ratio - average propensity to consume (ratio).

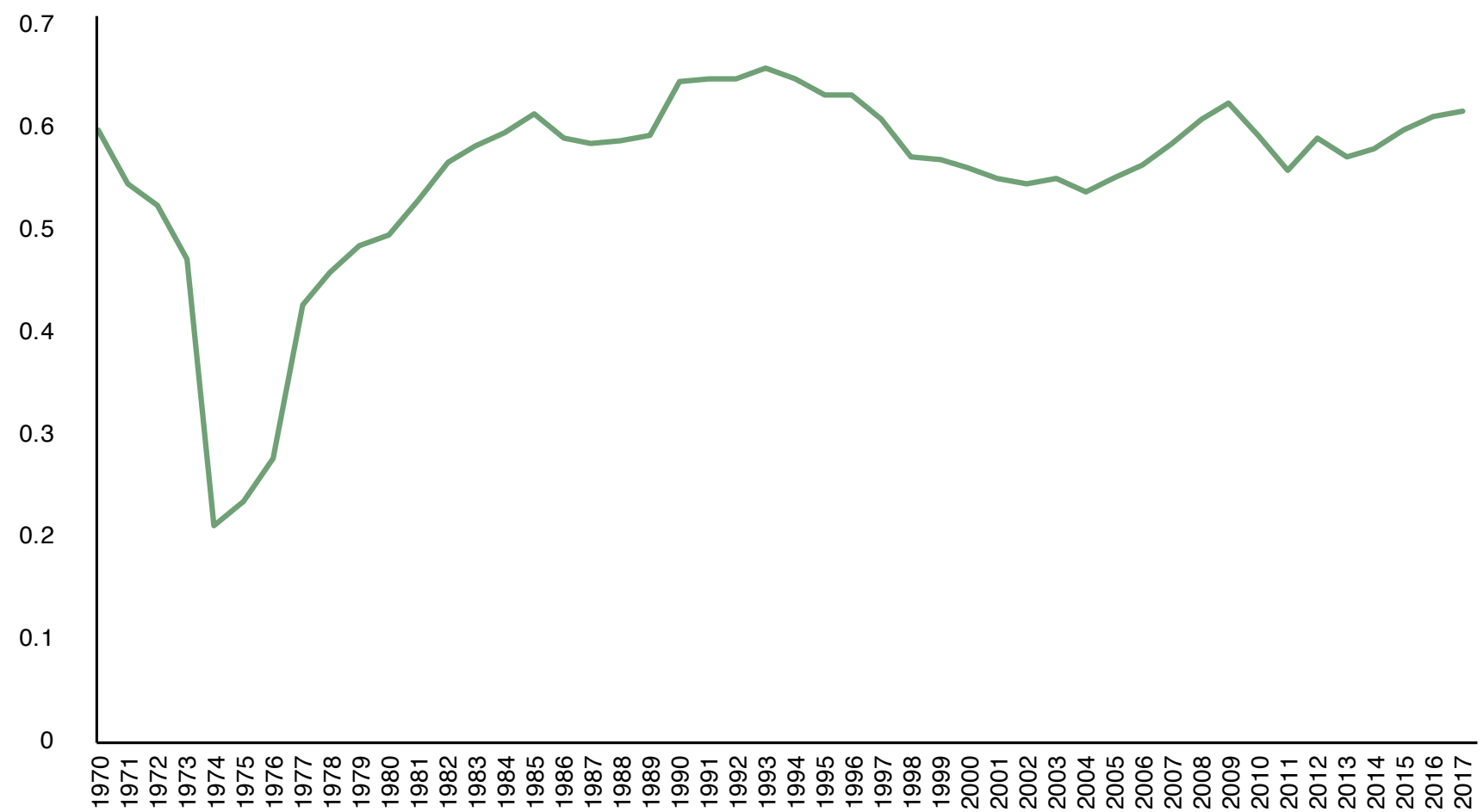

Source: KAPSARC analysis. 
O ur empirical representation of the consumption function takes into account the consuming behavior of the private sector and assumes that the relevant driver is the income attributable to the non-oil sector of the Saudi economy.

We assume that the relevant wealth concept is financial wealth (we do not consider real wealth because it is less clear what type of effect the variation in housing prices can have on current consumption).

The inflation rate $\pi$ is defined as the rate of change of the consumer price index (CPI). The real interest rate $r$ is defined as the short-term rate on U.S. dollar deposits deflated with the rate of change of the consumer price index: $r=\left(1+r_{U S D}\right) /(1+\pi)$.

Empirical macroeconomic evidence of the relationship between income and savings has abundantly shown that the typical life cycle model (Ando-Modigliani 1963; Modigliani-Brumberg 1980) provides an elegant micro foundation but is often inconclusive in the quantitative determination of the parameters of interest, for it relies on aggregated data which do not have enough detailed information.

Nonetheless, econometric estimation of the relationship between consumption income and wealth through fitting a consumption function remains a cornerstone of the explanation of macroeconomic systems, both from a positive analysis viewpoint (Muellbauer 1994) and from a normative analysis viewpoint.

It is therefore worthwhile analyzing such a relationship in a macro model, following the usual simplifying assumptions which allow us to specify a linear consumption function, where the savings rate depends on the interest rate (intertemporal substitution effect), on the wealth-income ratio (capturing the optimizing life cycle behavior) and on a set of other structural variables (for example, socio-economic variables).

For the purposes of this paper, we have defined labor income and total disposable income as $y$ land $y$ respectively (noting that $y=y^{l}+r w$ ), the growth rate in the steady state of real income as $g$, wealth as $w$ and interest rate as $r$, while $z$ is a vector of other relevant structural determinants. The simple consumption function:

$$
c=a y^{l}+\beta w
$$

where $a$ and $\beta$ are approximately constant coefficients can be rewritten, using $y=y^{l}+r w$ to capture the life cycle hypothesis:

$$
c=a(z) y+\beta(r, g) w
$$

where the coefficients are now more complex: $a(z)$ captures aggregation of the structure of preferences, productivity growth and population growth and $\beta(r, g)$ captures productivity growth and interest effects (Modigliani, 1986). It is important to be able to linearize Equation 2 for empirical estimation, considering that the relevant coefficients are non-linear functions of other variables. According to Modigliani (1986), in $a(z)$, the $z$ vector may include productivity and growth rate $g$ and other potential structural determinants, with coefficients capturing the influence of heterogeneous socio-demographic influences on the propensity to consume out of income. Thus, the motivation for linearizing around long-run equilibrium values of $g, r$ and $w / y$ is to obtain an equation where the relevant propensities to consume are recoverable from the empirical estimation in a linear relation, as follows: 


$$
c / y=a_{0}+\sum a_{j} z_{j}+b_{1} r+b_{2} g+d(w / y)
$$

Equation 3 is an approximate relation, where the heterogeneous socio-demographic determinants (variables $z_{j}$ ) could capture aggregation effects, which may not be justifiable based on a rigorous theoretical specification of the individual life cycle model. On this point see Ostry-Levy (1995), who investigated the effect of heterogeneity of individual responses to future income uncertainty (the idea of 'saving for a rainy day') as a shifting factor of the aggregate result and Sarel (1995) who introduced labor productivity changing with the age structure of the population as a determinant of macroeconomic growth.

With these caveats, we consider Equation 3 to be an approximation of the long-run equilibrium representation of the relationship between consumption, income and wealth in the empirical estimation - extensively estimated in the literature in the ECM form. For instance, applications to the U.S., the United Kingdom, some of the Nordic countries, Japan and Australia are provided by Muellbauer (1994), Church et al. (1994) and Hendry (1994), who between them have reviewed some 20 years of econometric estimation evidence.

In order to estimate an ECM of consumption, income and wealth, we conducted a preliminary integration and cointegration analysis among these variables. The unit roots test allows for identification of the stationarity properties of the series and the possible existence of a long-run (cointegrating) relation and to avoid the risk of estimating spurious correlations. We used the augmented Dickey-Fuller (ADF) test (Dickey and Fuller 1979) and the weighted symmetric (WS) test (Pantula et al. 1994). Note that the period being covered is short and the results (Johansen Maximum Likelihood method) are thus weak, due to scarce degrees of freedom, although reasonable.
We tested the stationarity properties of the series analyzed to avoid the risk of spurious regression, as shown in Table 2. We have tested the integration relation with the usual specifications, without a constant ("none"), with a constant ("const"), and with a trend ("trend"). Significant test values at the $5 \%$ level are denoted by “*”. The lag length is determined according to the Akaike information criterion (with a maximum set by the program equal to 10). According to the ADF and WS unit root tests we cannot reject the null result for consumption, income and wealth, finding the usual results that these series are integrated of order one, for the whole sample period shown in the left columns for each test displayed in Table 2.

The tests showed that the CPI is not stationary, while the real interest rate is stationary. We also found that the log first differences of the variables were stationary. This latter result is important, given that the ECM is specified with the dependent variable as the (log) difference of consumption. We repeated the test to check whether there were relevant differences in the post oil-shocks period (post 1982). Without engaging in a structural break test, we can infer from visual examination of the data (Figure 2) that in the 1970s there was a high variability in the relationship between Saudi consumption and income due to the sudden income increase generated by the first (1973) oil crisis and the more sluggish response of consumption, where the ratio of consumption to income dropped considerably below 0.4 in the period 1974-1977 before increasing gradually. The large consumption/income ratio fluctuation ended in 1982. Conducting the test for the sub-period 1982-2017 showed the same results, as shown in the right-hand columns for each test in Table 2. The results were confirmed when varying the subperiod to 1981-2017 and 1983-2017. 
Table 2. Stationarity test results.

\begin{tabular}{|c|c|c|c|c|}
\hline & \multicolumn{2}{|c|}{ ADF test (n. lags) } & \multicolumn{2}{|c|}{ WS test (n. lags) } \\
\hline \multirow[b]{2}{*}{ c none } & \multirow{2}{*}{$1970-2017$} & $1982-2017$ & $1970-2017$ & $1982-2017$ \\
\hline & & $-1.050 \quad(2)$ & $-0.657 \quad(3)$ & $-0.396 \quad(3)$ \\
\hline const & $0.36 \quad(3)$ & 0.755 & $-1.299 \quad(3)$ & $2.970 \quad(3)$ \\
\hline trend & $1.66 \quad(3)$ & $1.678 \quad(2)$ & & \\
\hline y none & $-2.075 \quad(9)$ & $-2.548 \quad(9)$ & $-0.469 \quad(9)$ & $2.699 \quad(9)$ \\
\hline const & $1.297 \quad(9)$ & $2.281 \quad(9)$ & $-1.243 \quad(9)$ & $0.985 \quad(9)$ \\
\hline trend & $2.536 \quad(9)$ & $2.371 \quad(9)$ & & \\
\hline w none & $-1.473 \quad(8)$ & $-1.252 \quad(9)$ & -0.254 & $-0.314 \quad(3)$ \\
\hline const & $-0.461 \quad(8)$ & $1.174 \quad(9)$ & $-4.465^{\star}(3)$ & -2.122 \\
\hline trend & $1.976 \quad(8)$ & $2.054 \quad(9)$ & & \\
\hline r none & $-3.952^{*}(3)$ & $-1.495(10)$ & $-2.617 \quad(2)$ & $-1.565(10)$ \\
\hline const & $4.779^{*}(3)$ & $1.399 \quad(10)$ & $13.16^{*} \quad(2)$ & $9.564^{*}(10)$ \\
\hline trend & $-3.736^{*}(3)$ & $-1.581 \quad(10)$ & & \\
\hline CPI none & $-2.73 \quad(4)$ & $0.863 \quad(10)$ & $-0.85 \quad(9)$ & $-0.71 \quad(3)$ \\
\hline const & $2.64 \quad(4)$ & $-0.914(10)$ & $11.51^{*} \quad(9)$ & $26.41^{\star}(3)$ \\
\hline trend & $-2.51 \quad(4)$ & $1.276 \quad(10)$ & & \\
\hline \multicolumn{5}{|c|}{ Log changes ADF tests (n. lags) } \\
\hline & $1970-2017$ & \multicolumn{2}{|c|}{$1982-2017$} & \\
\hline \multicolumn{5}{|l|}{$d \ln (c)$} \\
\hline none & $-4.535^{\star} \quad(3)$ & \multicolumn{2}{|l|}{$-2.592^{*} \quad(2)$} & \\
\hline const & $3.568^{\star} \quad(3)$ & \multicolumn{2}{|l|}{$2.273 \quad(2)$} & \\
\hline \multicolumn{5}{|l|}{$d \ln (y)$} \\
\hline none & $-5.769^{\star} \quad(3)$ & \multicolumn{2}{|l|}{$-3.304^{*} \quad(2)$} & \\
\hline const & $2.594^{\star} \quad(3)$ & \multicolumn{2}{|l|}{$3.058^{*} \quad(2)$} & \\
\hline \multicolumn{5}{|l|}{$d \ln (w)$} \\
\hline none & $-2.680^{\star} \quad$ (3) & \multicolumn{2}{|l|}{$-1.996 \quad$ (2) } & \\
\hline const & $2.454 \quad$ (3) & \multicolumn{2}{|l|}{$7.787^{*} \quad$ (2) } & \\
\hline
\end{tabular}

Note: ADF: Augmented Dickey-Fuller; WS: Weighted symmetric; $n$. lags: the number of lags is determined according to the Akaike information criterion; *: test significance at $5 \%$ level.

Source: KAPSARC.

In addition, we found evidence of plausible cointegrating vectors, both in levels and logs; of the variables for the simple relation between consumption and income $(c, y)$; and for the more complex relation between consumption, income and wealth $(c, y, w)$, as shown in Table 3. We checked the relation in levels so as to corroborate the hypothesis that a plausible long-run relation exists. Indeed, the result showed a positive relation between consumption and income of about 0.7-0.9 and an income-wealth relation of about 0.2 . We also found that the log relation between consumption 
Table 3. Cointegration test results.

$1970-2017$

$1982-2017$

\begin{tabular}{|c|c|c|c|c|}
\hline$(c, y)$ & $(-1,0.86)$ & & $(-1,0.87)$ & \\
\hline & $\begin{array}{l}\text { Test stat } \\
-2.03\end{array}$ & $\begin{array}{l}\text { Num.lags } \\
1\end{array}$ & $\begin{array}{l}\text { Test Stat } \\
-1.41\end{array}$ & $\begin{array}{l}\text { Num.lags } \\
1\end{array}$ \\
\hline \multirow[t]{2}{*}{$(c, y, w)$} & $(-1,0.83,0.25)$ & & $(-1,0.87,0.29)$ & \\
\hline & $\begin{array}{l}\text { Test stat } \\
-3.43\end{array}$ & $\begin{array}{l}\text { Num.lags } \\
1\end{array}$ & $\begin{array}{l}\text { Test Stat } \\
-3.20\end{array}$ & $\begin{array}{l}\text { Num.lags } \\
1\end{array}$ \\
\hline \multirow[t]{2}{*}{$(I c, l y)$} & $(-1,0.98)$ & & & \\
\hline & $\begin{array}{l}\text { Test stat } \\
-2.98\end{array}$ & $\begin{array}{l}\text { Num.lags } \\
1\end{array}$ & & \\
\hline \multirow[t]{2}{*}{$(I c, I y, I w)$} & $(-1,0.73,0.26)$ & & & \\
\hline & $\begin{array}{l}\text { Test stat } \\
-3.28\end{array}$ & $\begin{array}{l}\text { Num.lags } \\
1\end{array}$ & & \\
\hline
\end{tabular}

Source: KAPSARC.

and income was unitary, confirming that the consumption/income ratio is constant in the long run.

The preliminary test results allowed us to consider a general dynamic autoregressive relation between consumption and income:

$$
c_{t}=a_{0}+\sum a_{j} c_{t_{j}}+\sum b_{j} y_{t-j} \quad j=1,2, \ldots N
$$

Equation 4 can be restricted to an ECM formulation. This allowed us to capture short-term effects of variations in the exogenous variables, resulting in a long-term mathematical structure consistent with economic theory, i.e., a constant consumption/ income ratio in the long-run steady state (Hendry 1983). It is possible to recover the long-run relation from the estimation of a general autoregressive formulation with an appropriate hypothesis (Davidson et al. 1978). We can restrict $j=1$ to obtain $y_{t}=a_{1} y_{t-1}+b_{1} x_{t}+b_{2} x_{t-1}$. We impose $a_{1}+b_{1}+b_{2}=1$ and define $a_{1}=1-\gamma$, which implies $b_{1}=b_{2}-\gamma$, to obtain the short-term form, approximating the growth rate of the variables with the change in logs. Thus we obtain a formulation which is given by the growth rate of $c$ as a function of the growth rate of $c$ and a term constituted by the log of lagged ratio $c / y$ :

$$
d \ln (c)=a_{0}+a_{1} d \ln (y)+\gamma(\ln c-\ln y)
$$

In this way, a flexible short-term relation is captured by the first term after the constant, while the long-run steady state relation can be recovered, assuming a long-run steady state real growth rate $g$ for both variables $c$ and $y$, we obtain: $\left(g-a_{0}-a_{1} g\right) / \gamma$ $=(\ln c-\ln y)$. From the latter, defining:

$$
b=\exp \left\{\left(g-a_{0}-a_{1} g\right) / a_{2}\right\}
$$

we obtain the long-run MPC as a function of the estimated parameters, yielding $b=c / y$, or:

$$
c=b y
$$


Equation 7 is the long-term relation between $c$ and $y$ derived from the short-term relation - as seen in Equation 5, which is the basis for the long-term consumption function, with the interpretation of $b$ as the long-run MPC.

Given the aforementioned results, we proceeded to estimate an ECM, experimenting with two versions of the ECM empirical consumption function: the first is consumption and income and is linear in the parameters, while the second is consumption, income and wealth and is non-linear in the parameters (see also Banerjee et al. 1986, and Phillips-Loretan 1991). We followed the approach of Davidson et al. (1978), Hendry (1983) and Hendry and Nielsen (2007). The first version (below) is the linear ECM, which is linear in the parameters of the variables income, price and real interest rate:

$d \ln (c)=\theta_{0}+\theta_{1} d \ln (y)+\theta_{2} \pi+\theta_{3} r+\gamma[\ln (c)-\ln (y)]_{-1}$

where $\theta_{j}$ are short-term coefficients, $d \ln (c)$ is the log change of real consumption, $\pi$ is the rate of change of prices, $r$ is the real interest rate, $d \ln (y)$ is the log change of real income and $\gamma$ is the ECM adjustment coefficient. The long-run solution of Equation 8 is a linear consumption-income relation, which can be obtained assuming long-run steady state values for the real growth rate $g$, inflation $\pi^{*}$ and interest rate $r^{*}$, following the procedure described to obtain Equation 7 from Equation 5.

Define $b=\exp \left\{\left(g-\theta_{0}-\theta_{1} g-\theta_{2} \pi^{*}-\theta_{3} r^{*}\right) / \gamma\right\}$ and obtain: $c=b y$.

The second version of ECM is non-linear in the parameters. This is a version of the ECM which includes two variables, namely income and wealth as joint determinants of consumption, including income growth rate, price, real interest rate and wealth growth rate, $d \ln (w)$, of the form:

$$
\begin{aligned}
& d \ln (c)=\theta_{0}+\theta_{1} d \ln (y)+\theta_{2} \pi+\theta_{3} r+\theta_{4} d \ln (w) \\
& \quad+\gamma_{0}\left\{\ln (c)-\ln \left[(y)-\gamma_{1}(w)\right]\right\}_{-1}
\end{aligned}
$$

where, in addition to the other variables, $w$ is wealth, $d \ln (w)$ is the growth rate of wealth, and $\gamma_{0}$ and $\gamma_{1}$ are the adjustment coefficients of the non-linear ECM. We refer to Equation 9 as non-linear in the sense that the parameters $\gamma_{0}$ and $\gamma_{1}$ enter into a non-linear combination in the estimation procedure. 


\section{Empirical Results}

$\mathbf{T}$ able 4 shows the estimation results of the equations and coefficients (see Appendix for more detailed results). We have estimated Equations 8 and 9 with a maximum likelihood estimator (with consistent asymptotic variance). We have also tested a variant of the consumption/ income relation given in Equation 7, of the form $c=b y^{\delta}$, where $\delta$ may capture a data-driven nonlinearity in the consumption/income relation. We tested alternative values of $\delta=(0.8,0.9,1.1,1.2)$ against $\delta=1$ and obtained non-significant values based on a chi-square test at $1 \%$ confidence level (the maximum likelihood value is for $\delta=0.9$, with a test value chi-square $=5.4$, against the critical value of chi-square $=6.6$ ). Also, Hasanov et al. (2018) found an elasticity equal to 0.99 , not rejecting the one-to-one relationship between consumption and income, with the Wald test. From a statistical viewpoint, this allowed us to conclude that the Saudi consumption data support the longrun linear consumption/income relation.
In our estimations, the short-term adjustment coefficients and the long-term MPC are plausible, given that almost all of the parameters are significant at $1 \%$. In particular, the short-term impact coefficients have the expected sign and plausible magnitude in both Equations 8 and 9.

Note that the interest rate effect is negative, and significant, in Equation 8, but less so in Equation 9 when the wealth effect is explicitly specified.

It is also noteworthy that the crucial adjustment coefficient of the ECM is highly significant in both versions - more precisely, $\gamma$ is - 0.24 in Equation 8 and $\gamma_{0}$ is -0.55 in Equation 9.

On the basis of the estimated regressions, we show the short-run and long-run MPC out of income and wealth in Table 5.

The short-run values of the income propensity are the estimated coefficient of the log change of income $\theta_{1}$ in Equations 8 and 9.

Table 4. Parameter estimates - full information maximum likelihood.

Equation 8

\begin{tabular}{l|l|l|l}
\hline Parameter & Estimate & Parameter & Estimate \\
\hline$\theta_{0}$ & $-.065^{\star *}$ & $\theta_{0}$ & .058 \\
\hline$\theta_{1}$ & $.412^{\star *}$ & $\theta_{1}$ & $.257^{\star}$ \\
\hline$\theta_{2}$ & $-.491^{\star \star}$ & $\theta_{2}$ & $-.335^{\star *}$ \\
\hline$\theta_{3}$ & $-.049^{\star *}$ & $\theta_{3}$ & -.0018 \\
\hline$\gamma$ & $-.243^{\star *}$ & $\theta_{4}$ & $-.0175^{\star *}$ \\
\hline & & $\gamma_{0}$ & $-.546^{\star *}$ \\
\hline s.e. of regression & & $\gamma_{1}$ & $-.068^{\star *}$ \\
\hline R-squared & 0.06 & s.e. of regression & 0.08 \\
\hline D-W & .79 & R-squared & .61 \\
\hline
\end{tabular}

Note: ${ }^{* *}$ significant at $1 \%$; ${ }^{*}$ significant at $5 \%$. s.e.: standard error; D-W: Durbin-Watson test 
Table 5. Marginal propensities to consume (MPC) in the short and long run.

Equation 8

\begin{tabular}{l|l|l}
\hline Marginal propensity to consume out of income \\
\hline Year & short run & long run \\
2018 & $0.412(3.02)$ & $0.729(19.15)$ \\
\hline
\end{tabular}

Wald test for the hypothesis that the two parameters are jointly zero: $\mathrm{CHISQ}(2)=377.19$

P-value $=0.000$

Equation 9

\begin{tabular}{l|l|l}
\hline \multicolumn{2}{l}{ Marginal propensity to consume out of income } & long run \\
\hline Year & short run & $0.949(9.93)$ \\
2018 & $0.128(1.40)$ & \multicolumn{2}{l}{} \\
\hline \multicolumn{1}{l|}{ Marginal propensity to consume out of wealth } & long run \\
\hline Year & short run & $0.065(13.08)$ \\
2018 & $-0.018(4.67)$ &
\end{tabular}

Wald test for the hypothesis that the 4 parameters are jointly zero: $\mathrm{CHISQ}(4)=180.79 \quad \mathrm{P}$-value $=0.000$

Note: values computed around long-run values of $\mathrm{w} / \mathrm{y}^{*}, \mathrm{r}^{*}, \pi^{*}$, and $\Delta \log \mathrm{y}^{*}$. $\mathrm{t}$ values in parentheses.

Source: KAPSARC.

The short-run value of the wealth propensity is the short-run coefficient $\theta_{4}$ in Equation 9.

The long-run values are computed assuming long-run steady-state values for the variables.

Note that all values are highly significant, and the Wald test of joint significance is high.

In the first version of the ECM (Equation 8) the immediate response of consumption to changes in income is 0.41 , and the long-run value is 0.73 . In addition, the speed of adjustment of the error correction is about $39 \%$ per year. The short-run price effect is around -0.49 . These values imply that over the course of 2018 a positive income shock of 100 Saudi riyals would generate an additional consumption of just over 41 Saudi riyals in the first year, half of that in 1.7 years, and almost 73 Saudi riyals in the long-run.
The second version of the ECM (Equation 9) includes the wealth effect. It provides a more detailed explanation of the consumption/income relation with respect to the simple linear model.

In the non-linear model, the immediate response of consumption to changes in income is lower, at 0.13 , and the long-run value is higher, at 0.95 . In addition, the speed of adjustment of the error correction is about $54 \%$ per year. The short-run price effect is around -0.33 . This model captures a more gradual dynamic of the transition from the short-run to the long-run, from 0.13 to 0.95 , with a higher speed of adjustment. The long-run propensity in the non-linear ECM is also higher $(0.95)$ than the value of the simple model $(0.73)$. This is relevant information for policymakers when designing national fiscal policies that may influence consumer income. 
The values in Table 5 imply that in 2018 an income shock of 100 Saudi riyals in Saudi Arabia could generate an additional consumption of 13 in the first year and half of the effect (6.5) in about 1.3 years and the long-run consumption effect of 95 Saudi riyals.

There is also a response of consumption to changes in wealth evident in Equation 9. The link between consumption and wealth is smaller than the consumption-income relation, as it is more difficult to use wealth for immediate consumption. In the short run, an increase in wealth may spur expectations of an increase in volatility or expectations of positive housing price shocks. Both may induce precautionary increased saving behavior by households, i.e., lower consumption (Cooper 2016). According to the estimates, there is a small negative short-run effect of around -0.02 and a long-run effect of around 0.06 , which is consistent with the above interpretation. This suggests that a long-run increase in wealth of 100 Saudi riyals leads to a consumption increase of 6 Saudi riyals.

At this point, it is worthwhile recalling the main stylized results mentioned in the literature in order to compare the results for Saudi Arabia with international cases.

The main results of the literature can be summarized as follows:

The long-run MPC can range from 0.5 to 0.9 , depending on the economy and the type of consumers.

The effects are more pronounced in more advanced economies, and where the population is older, and are similar in many Asian and Latin American countries. In addition, the effect on consumption may tend to be asymmetric (i.e., negative shocks exert a bigger impact than positive shocks).
Consumers who can freely borrow and save have a lower long-term MPC out of a permanent income shock, at around 0.50-0.77.

Consumers who are unable to borrow show a higher long-run MPC, of around 0.93.

The MPCs from a transitory income shock are much lower, but the magnitudes are different: 0.05 for those who are free to borrow and 0.18 for those who are constrained.

The short-run income effect is typically lower than the long-run effect. It is around 0.15 in advanced economies (e.g., 0.17 in the U.S.) and can reach 0.50 in emerging economies, although it is not always precisely determined.

The MPC out of wealth is around 0.02-0.07 (with relatively higher values for liquid assets - up to three times higher, when considered separately). The interest rate effect is around -0.2 .

The dynamic ECM adjustment coefficient is in the 0.2-0.5 range, implying that the half-life of the shock effect is realized in a period of between one to three years.

Comparing the results for the Kingdom, we note that these values appear to be slightly lower than the typical estimation for advanced economies. However, the results are consistent with the Ando-Modigliani model prediction because Saudi Arabia has a young population and a lower income per capita level than many advanced economies. These characteristics of Saudi Arabia's population structure suggest that the relatively higher propensity to consume, i.e., a relatively lower savings capacity than in many comparable economies, results in less accumulation of wealth 
and therefore a lower propensity to consume out of accumulated wealth.

In addition, we can infer the effect of a VAT increase from the price effect. Using the estimated coefficient of the two models, we estimate that a $1 \%$ increase in the price level can have a negative effect on consumption of $0.3 \%$ to $0.49 \%$. Working on the assumption that the imposition of
VAT leads to a onetime adjustment in the price of applicable products, the effect of the January 2018 introduction of a 5\% VAT rate in the Kingdom generated an overall rise in prices of around 1\% over the course of the year. Note that this is an assumption ceteris paribus, i.e., all other things being equal. These values imply that in 2018 Saudi VAT will have a negative impact of $-3 \%$ on Saudi household consumption. 
his paper makes a new contribution to the literature by estimating a fully microfounded life cycle model for Saudi Arabian consumption for the period 1970-2017, following the seminal work of Ando-Modigliani (1963).

Our econometric estimation of the dynamic consumption function for Saudi Arabia included a full account of income and wealth effects on the consumption behavior of Saudi households, providing a basis for a more comprehensive appraisal of the effects of the Kingdom's recent economic policy reforms (2017-2018).

Our analysis showed significant differences in consumers' intertemporal optimizing behavior, highlighting quantitative differences in short- and long-term responses. The econometric results showed the existence of statistically significant effects of both an income and a wealth effect and also of consumer price and real interest rate effects.

This estimation of the consumption function in Saudi Arabia is the first attempt to include dynamic responses to both income and wealth in the specification of the macro consumption equation.

In summary, the results imply that in 2018 a given positive income shock of $1 \%$ can generate additional consumption of $0.41 \%$ in the first year, half that effect in about 1.7 years and a long-run effect of $0.73 \%$. Also, a $1 \%$ positive shock in wealth can generate a $0.02 \%$ increase in consumption in the short run and a $0.06 \%$ rise in the long run.

Based on the estimated function and the assumption of ceteris paribus, a simulation for 2018 of the additional effect of VAT on household consumption in the Kingdom equated to a onetime $-0.3 \%$ impact.
In addition, we can provide evidence of the relative magnitude of temporary and permanent effects of income shocks on consumption to provide policymakers with a more accurate evaluation of the impact of different measures of tax and price reforms. The broad relevance of these results for economic policy in the Kingdom can be found in the quantification of the responses of consumption and savings to monetary policy (via the interest rate effect) and fiscal policy, namely taxation policy (via the current income effect).

The quantification of the MPC of the aggregate private sector is a key pillar in the design of national macroeconomic policy scenarios, if only because it feeds directly into the computation of the policy multiplier. Notwithstanding the complexity of the leakages in the macroeconomic system, stimulating private income generates a stimulus in consumption and a multiplier effect on aggregate demand and, therefore, on GDP growth.

We respectfully suggest that more research in this field is needed, especially work on the Saudi economy and emerging market economies. For example, an analysis of the MPC in the Kingdom's economy at disaggregated levels is needed in order to understand the private sector's added value to the growth in Saudi Arabia's non-oil GDP.

Another interesting area for further research could be the economies of the other member states of the Gulf Cooperation Council, given that they are somewhat interconnected, have structural similarities, and are almost all oil exporters.

Lastly, empirically testing and comparing the results of the new theorems on the household consumption function could offer national policymakers useful data. 


\section{References}

Al-Bashir, Faisal Safooq. 1977. A Structural Econometric Model of the Saudi Arabian Economy: 1960-1970. New York: John Wiley and Sons.

Algaeed, Abdulaziz Hamad. 2016. "Money Supply as a Conduit of the Consumption in the Saudi Economy: A Co-integration Approach." International Journal of Economics, Finance and Management Sciences, 4(5): 269-274.

Ando, Alberto and Franco Modigliani. 1963. "The 'LifeCycle' Hypothesis of Saving: Aggregate Implications and Tests", The American Economic Review, 53, 1, 55-84.

Attanasio Orazio. and Guglielmo Weber. 1993.

"Consumption Growth, the Interest Rate and

Aggregation", Review of Economic Studies, vol.60, n. 204, pp. 631-649.

Attanasio Orazio and Luigi Pistaferri. 2016. "Consumption Inequality", Journal of Economic Perspectives, 30(2), 3-28.

Banerjee Anindya, Juan J. Dolado, David F. Hendry, and Gregor W. Smith. 1986. "Exploring Relationships in Econometrics Through Static Models: Some Monte Carlo Evidence", Oxford Bulletin of Economics and Statistics, $48,253-277$.

Bick Alexander and Sekyu Cho. 2013. "Revisiting the effect of household size on consumption over the lifecycle", Journal of Economic Dynamics \& Control 37, 2998-3011.

Carroll, Christopher D., Jiri Slacalek, and Kiichi Tokuoka. 2014. "The Distribution of Wealth and the MPC: Implications of New European Data," The American Economic Review, 104(5): 107-111.

Church Keith, Peter Smith and Kenneth Wallis. 1994. "Econometric Evaluation of Consumers' Expenditure Equations", Oxford Review Economic Policy, 10 (2).

Cicowiez Martin and Hans Lofgren. 2017. "Building Macro SAMs from Cross-Country Databases Method and Matrices for 133 Countries", World Bank, Development Economics Development Prospects Group, Policy Research Working Paper 8273, December 2017.
Cooper David. 2016. "Wealth Effects and Macroeconomic Dynamics", Journal of Economic Surveys, 30 (1): 34-55.

European Central Bank (ECB). 2016. "The Eurosystem household finance and consumption survey. Results from the second wave", European Central Bank, Statistics Paper, No 18, December 2016 - Household Finance and Consumption Network.

Davidson, James, E. H., David Hendry, Frank Srba, F., and Stephen Yeo. 1978. "Econometric modelling of the aggregate time-series relationship between consumers' expenditure and income in the United Kingdom".

Economic Journal, 88, 661-692. Reprinted in Hendry, David. 1993 Econometrics: Alchemy or Science? Oxford: Blackwell Publishers.

Davis, Morris A. and Michael G. Palumbo. 2001. "A Primer on the Economics and Time Series Econometrics of Wealth Effects," Washington, DC: Federal Reserve Board, Finance and Economics Discussion Series, Discussion Paper 2001-09.

Dickey, David, and Wayne Fuller. 1979. "Distribution of the estimators for autoregressive time series with a unit root". Journal of the American Statistical Association, 74 (366): 427-431.

Duesenberry, John S. 1949. Income, Saving and the Theory of Consumption Behavior, Cambridge, Mass.: Harvard University Press.

Fagan, Gabriel, Jerome Henryand Ricardo Mestre. 2005. "An area-wide model for the euro area", Economic Modelling 22: 39-59.

Friedman, Milton. 1957. "The permanent income hypothesis", in M. Friedman, A Theory of the Consumption Function, Princeton, NJ: Princeton University Press (for NBER): 20-37.

Hall Robert E. 1978. "Intertemporal Substitution in Consumption", The Journal of Political Economy, 96 (2): 339-357.

Hasanov, Fakhri, Frederic Joutz and Jeyhun Mikayilov. 2018. "The impact of the increased domestic energy prices on the Saudi Arabian economy. Insights from 
KGEMM", ITISE 2018, International Conference on Time Series and Forecasting. Proceedings of Papers 2: 795-797.

Hendry, David F. 1983. "Econometric Modelling: The 'Consumption Function' in Retrospect", Scottish Journal of Political Economy, 30:193-220.

Hendry David. 1994. "HUS Revisited", Oxford Review of Economic Policy, 10 (2).

Hendry, David and Bent Nielsen. 2007. Econometric Modeling: A Likelihood Approach. Princeton, N.J.: Princeton University Press.

Ibrahim, Mohamed Abbas. 2014. "The Private Consumption Function in Saudi Arabia", American Journal of Business and Management 3 (2): 109-116.

International Monetary Fund (IMF). 2006. Financial Soundness Indicators: Compilation Guide, March. Washington, D.C.: International Monetary Fund, ISBN 1-58906-385-6.

Jappelli Tullio, and Luigi Pistaferri. 2010. "The Consumption Response to Income Changes", Annual Review of Economics 2: 479-506. www.annualreviews. org.

Kaplan Greg and Giovanni Violante. 2010. "How Much Consumption Insurance Beyond Self-Insurance?" American Economic Journal: Macroeconomics 2 (October 2010): 53-87 http://www.aeaweb.org/articles. php?doi=10.1257/mac.2.4.53.

Keynes John M. 1936. The General Theory of Employment, Interest and Money. London: Harcourt Brace Jovanovich, 1964 (reprint of the 1936 edition).

Modigliani Franco. 1986. "Life Cycle, Individual Thrift and the Wealth of Nations", American Economic Review 76: 297-313.

Modigliani, Franco, and Richard H. Brumberg. 1954. "Utility analysis and the consumption function: an interpretation of cross-section data," in K.K. Kurihara, ed., Post-Keynesian Economics, New Brunswick, NJ: Rutgers University Press: 388-436.
Modigliani Franco and Richard H. Brumberg. 1980. "Utility Analysis and Aggregate Consumption Functions: An Attempt at Integration", in Franco Modigliani, Collected Papers, Cambridge: MIT Press.

Molana Hassan. 1991. "The Time Series Consumption Function: Error Correction, Random Walk and the Steady-State." The Economic Journal 101: 382-403.

Muellbauer John. 1994. "The Assessment: Consumer Expenditure." Oxford Review of Economic Policy 10 (2): $1-41$.

Muellbauer, John and Ralph Lattimore. 1995. "The Consumption Function: A Theoretical and Empirical Overview." In M. Hashem Pesaran and Michael R. Wickens, eds., Handbook of Applied Econometrics. Oxford: Blackwell.

Ostry Jonathan and Joaquim, Levy J. 1995. "Household Saving in France: Stochastic Income and Financial Deregulation." IMF Staff Papers 42 (2): 375-397.

Pantula, Sastry G., Graciela Gonzalez-Farias, and Wayne A. Fuller. 1994. "A Comparison of Unit-Root Test Criteria." Journal of Business and Economic Statistics, October: 449-459.

Peltonen, Tuomas A., Ricardo M. Sousa and Isabel S. Vansteenkiste. 2012. "Wealth effects in emerging market economies." International Review of Economics and Finance 24: 155-166.

Phillips Peter C. B. and Mico Loretan. 1991. "Estimating Long-run Economic Equilibria", Review of Economic Studies 58: 407-436.

Rossi, Nicola and Iganzio Visco. 1994. "Private saving government deficits", in A. Andro, L. Guiso and I. Visco, eds., Saving Accumulation of Wealth. Cambridge:

Cambridge University Press, pp, 70-105.

Sarel Michael. 1995. "Demographic Dynamics and the Empirics of Economic Growth." IMF Staff Papers, 42 (2): 398-410

Slacalek, Jiri. 2009. "What Drives Personal Consumption? The Role of Housing and Financial Wealth", The B.E. Journal of Macroeconomics 9 (1): 1-37. 
Smets Frank and Raf Wouters. 2003. "An estimated Stochastic Dynamic General Equilibrium Model of the Euro Area." Journal of the European Economic Association 1(5): $1123-1175$.

Sousa, Ricardo M. 2008. "Financial wealth, housing wealth, and consumption". International Research Journal of Finance and Economics 19: 167-191.

Sousa, Ricardo M. 2009. "Wealth effects on consumption: evidence from the Euro area", European Central Bank Working Paper Series 1050, May, http:// www.ecb.europa.eu
Tawi, Saleh Ahmed. 1984. A macroeconometric model for the economy of Saudi Arabia. Retrospective Theses and Dissertations. Iowa State University, 17096. http://lib. dr.iastate.edu/rtd/17096

Vitek, Francis. 2018. "The Global Macrofinancial Model", IMF, Monetary and Capital Markets Department, IMF Working Paper, WP/18/81, https:// www.imf.org/en/Publications/WP/lssues/2018/04/09/ The-Global-Macrofinancial-Model-45790 
Notes

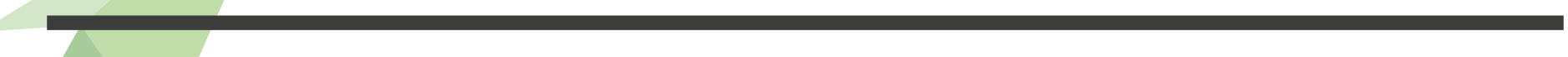


Table A1. Consumption (private final consumption expenditure) and income (GDP non-oil at 2010 constant prices).

\begin{tabular}{|c|c|c|c|}
\hline Year & Private consumption & GDP non-oil & Consumption / income ratio \\
\hline 1970 & 61758.51 & 103733.1 & 0.595 \\
\hline 1971 & 60965.46 & 112704.7 & 0.541 \\
\hline 1972 & 66976.17 & 128210.3 & 0.522 \\
\hline 1973 & 71498.28 & 152999.2 & 0.467 \\
\hline 1974 & 44286.76 & 212081.1 & 0.209 \\
\hline 1975 & 60920.29 & 263201.9 & 0.231 \\
\hline 1976 & 73662.92 & 269778.3 & 0.273 \\
\hline 1977 & 122366.3 & 289293.8 & 0.423 \\
\hline 1978 & 140343.7 & 307338.5 & 0.457 \\
\hline 1979 & 155713.6 & 322949.5 & 0.482 \\
\hline 1980 & 172924.6 & 351580.2 & 0.492 \\
\hline 1981 & 203183.7 & 386433.5 & 0.526 \\
\hline 1982 & 232086 & 412234.4 & 0.563 \\
\hline 1983 & 244087.7 & 421864.8 & 0.579 \\
\hline 1984 & 247930.5 & 419463.7 & 0.591 \\
\hline 1985 & 254540 & 416799.3 & 0.611 \\
\hline 1986 & 232275.6 & 395145 & 0.588 \\
\hline 1987 & 228231.1 & 393128.5 & 0.581 \\
\hline 1988 & 232339.4 & 397500.1 & 0.585 \\
\hline 1989 & 238980.5 & 405551.4 & 0.589 \\
\hline 1990 & 269124.4 & 419439.2 & 0.642 \\
\hline 1991 & 276383.8 & 429513.8 & 0.643 \\
\hline 1992 & 290635.7 & 450306.8 & 0.645 \\
\hline 1993 & 300991.3 & 459294 & 0.655 \\
\hline 1994 & 300465.3 & 465459.7 & 0.646 \\
\hline 1995 & 297175.1 & 472029 & 0.630 \\
\hline 1996 & 307469.5 & 488699.3 & 0.629 \\
\hline 1997 & 310733.6 & 514320 & 0.604 \\
\hline 1998 & 299767.6 & 526879.1 & 0.569 \\
\hline 1999 & 307103.8 & 542394 & 0.566 \\
\hline 2000 & 314979.6 & 565388.4 & 0.557 \\
\hline 2001 & 319699 & 583829.1 & 0.548 \\
\hline 2002 & 326936.2 & 603131.1 & 0.542 \\
\hline 2003 & 341679.3 & 625057.4 & 0.547 \\
\hline 2004 & 364827.6 & 683328.8 & 0.534 \\
\hline 2005 & 401522.1 & 733559.8 & 0.547 \\
\hline
\end{tabular}




\begin{tabular}{l|l|l|l}
\hline 2006 & 445642.3 & 794874.3 & 0.561 \\
\hline 2007 & 503930 & 865420.9 & 0.582 \\
\hline 2008 & 565269.2 & 934643.8 & 0.605 \\
\hline 2009 & 615666.2 & 989774.3 & 0.622 \\
\hline 2010 & 639417.4 & 1084288 & 0.590 \\
\hline 2011 & 650434.9 & 1173161 & 0.554 \\
\hline 2012 & 726340.4 & 1237790 & 0.587 \\
\hline 2013 & 749694.2 & 1317127 & 0.569 \\
\hline 2014 & 795672.7 & 1381172 & 0.576 \\
\hline 2015 & 849475.3 & 1425400 & 0.596 \\
\hline 2016 & 867790 & 1428629 & 0.607 \\
\hline & 884836.9 & 1443072 & 0.613
\end{tabular}

Source: KAPSARC.

Table A2. Main variables - annual growth rates (interest rate in percentage level).

\begin{tabular}{l|l|l|l|l|l|l|l|l|l|l|l} 
Year & $\begin{array}{l}\text { Consumption } \\
\text { nominal }\end{array}$ & $\begin{array}{l}\text { GDP } \\
\text { nominal }\end{array}$ & $\begin{array}{l}\text { Consumption } \\
\text { real }\end{array}$ & $\begin{array}{l}\text { GDP } \\
\text { real }\end{array}$ & $\begin{array}{l}\text { GDP } \\
\text { deflator }\end{array}$ & $\begin{array}{l}\text { GDP } \\
\text { non-oil } \\
\text { real }\end{array}$ & \multicolumn{2}{l}{$\begin{array}{l}\text { CPI } \\
\text { rate }\end{array}$} \\
\hline 1971 & 9.1 & 33.2 & -1.3 & 20.5 & 10.5 & 8.6 & 10.5 & 5.01 & 37.6 & N/A \\
\hline 1972 & 11.0 & 24.3 & 9.9 & 22.9 & 1.1 & 13.8 & 1.1 & 4.67 & 28.4 & N/A \\
\hline 1973 & 18.9 & 38.3 & 6.8 & 24.2 & 11.4 & 19.3 & 11.4 & 8.42 & 40.4 & N/A \\
\hline 1974 & 55.1 & 191.0 & -38.1 & 16.2 & 150.4 & 38.6 & 150.4 & 10.24 & 61.0 & N/A \\
\hline 1975 & 54.1 & 2.1 & 37.6 & -8.9 & 12.1 & 24.1 & 12.1 & 6.44 & 73.9 & N/A \\
\hline 1976 & 40.9 & 37.3 & 20.9 & 17.8 & 16.6 & 2.5 & 16.6 & 5.27 & 22.5 & N/A \\
\hline 1977 & 79.5 & 15.7 & 66.1 & 7.1 & 8.1 & 7.2 & 8.1 & 5.64 & 24.6 & N/A \\
\hline 1978 & 26.3 & 4.3 & 14.7 & -5.2 & 10.1 & 6.2 & 10.1 & 8.22 & 43.6 & N/A \\
\hline 1979 & 36.6 & 37.8 & 11.0 & 11.9 & 23.1 & 5.1 & 23.1 & 11.23 & 14.5 & N/A \\
\hline 1980 & 15.9 & 45.6 & 11.1 & 5.7 & 37.8 & 8.9 & 4.4 & 13.07 & 21.8 & N/A \\
\hline 1981 & 20.8 & 13.9 & 17.5 & 1.9 & 11.7 & 9.9 & 2.8 & 15.91 & 26.2 & N/A \\
\hline 1982 & 15.3 & -15.7 & 14.2 & -20.7 & 6.3 & 6.7 & 0.9 & 12.27 & 26.6 & N/A \\
\hline 1983 & 5.4 & -15.0 & 5.2 & -16.1 & 1.2 & 2.3 & 0.2 & 9.07 & 12.5 & N/A \\
\hline 1984 & 0.0 & -5.5 & 1.6 & -4.7 & -0.9 & -0.6 & -1.6 & 10.37 & 7.1 & N/A \\
\hline 1985 & -0.5 & -10.7 & 2.7 & -9.8 & -1.0 & -0.6 & -3.1 & 8.05 & 3.4 & 34.0 \\
\hline 1986 & -11.6 & -14.4 & -8.7 & 17.0 & -26.9 & -5.2 & -3.2 & 6.52 & 0.9 & -5.4 \\
\hline 1987 & -3.3 & -0.3 & -1.7 & -6.6 & 6.7 & -0.5 & -1.6 & 6.86 & 12.7 & 14.8 \\
\hline 1988 & 2.8 & 3.0 & 1.8 & 13.1 & -8.9 & 1.1 & 1.0 & 7.73 & 5.3 & 18.0 \\
\hline 1989 & 4.0 & 8.0 & 2.9 & -0.5 & 8.6 & 2.0 & 1.2 & 9.09 & 1.0 & 24.9 \\
\hline 1990 & 11.5 & 22.5 & 12.6 & 15.2 & 6.3 & 3.4 & -1.0 & 8.15 & 4.6 & -9.3 \\
\hline & & & & & & & & & \\
\hline
\end{tabular}




\begin{tabular}{|c|c|c|c|c|c|c|c|c|c|c|}
\hline 1991 & 6.6 & 12.5 & 2.7 & 15.0 & -2.2 & 2.4 & 3.8 & 5.84 & 14.5 & 85.8 \\
\hline 1992 & 4.2 & 3.8 & 5.2 & 4.0 & -0.2 & 4.8 & -0.9 & 3.68 & 2.5 & 14.0 \\
\hline 1993 & 4.8 & -3.0 & 3.6 & -1.4 & -1.7 & 2.0 & 1.2 & 3.17 & 3.4 & -4.0 \\
\hline 1994 & 1.1 & 1.6 & -0.2 & 0.6 & 1.1 & 1.3 & 1.3 & 4.63 & 3.4 & -26.7 \\
\hline 1995 & 4.1 & 6.1 & -1.1 & 0.2 & 5.8 & 1.4 & 5.2 & 5.92 & 2.3 & 5.7 \\
\hline 1996 & 3.7 & 10.7 & 3.5 & 2.6 & 7.9 & 3.5 & 0.2 & 5.39 & 6.8 & 12.1 \\
\hline 1997 & 0.7 & 4.6 & 1.1 & 1.1 & 3.5 & 5.2 & -0.3 & 5.62 & 5.5 & 29.5 \\
\hline 1998 & -3.8 & -11.5 & -3.5 & 2.9 & -14.0 & 2.4 & -0.3 & 5.47 & 4.0 & -28.2 \\
\hline 1999 & 0.3 & 10.4 & 2.4 & -3.8 & 14.7 & 2.9 & -2.1 & 5.33 & 7.9 & 43.2 \\
\hline 2000 & 2.3 & 17.1 & 2.6 & 5.6 & 10.8 & 4.2 & -1.1 & 6.46 & 4.3 & 11.4 \\
\hline 2001 & 0.6 & -2.9 & 1.5 & -1.2 & -1.7 & 3.3 & -1.3 & 3.69 & 6.6 & 7.8 \\
\hline 2002 & 0.3 & 3.0 & 2.3 & -2.8 & 6.0 & 3.3 & 0.1 & 1.73 & 14.8 & 2.2 \\
\hline 2003 & 3.7 & 13.8 & 4.5 & 11.2 & 2.3 & 3.6 & 0.5 & 1.15 & 6.9 & 110.0 \\
\hline 2004 & 9.2 & 20.6 & 6.8 & 8.0 & 11.7 & 9.3 & 0.3 & 1.56 & 18.8 & 94.7 \\
\hline 2005 & 9.9 & 26.8 & 10.1 & 5.6 & 20.1 & 7.4 & 0.5 & 3.51 & 11.6 & 112.2 \\
\hline 2006 & 13.3 & 14.7 & 11.0 & 2.8 & 11.6 & 8.4 & 1.9 & 5.15 & 19.3 & -49.7 \\
\hline 2007 & 18.2 & 10.4 & 13.1 & 1.8 & 8.4 & 8.9 & 5.0 & 5.27 & 19.6 & 58.7 \\
\hline 2008 & 20.7 & 25.0 & 12.2 & 6.2 & 17.7 & 8.0 & 6.1 & 2.97 & 17.6 & -52.5 \\
\hline 2009 & 13.0 & -17.4 & 8.9 & -2.1 & -15.7 & 5.9 & 4.1 & 0.56 & 10.7 & 29.2 \\
\hline 2010 & 8.0 & 22.8 & 3.9 & 5.0 & 16.9 & 9.5 & 3.8 & 0.31 & 5.0 & 10.9 \\
\hline 2011 & 6.6 & 27.1 & 1.7 & 10.0 & 15.5 & 8.2 & 3.7 & 0.30 & 13.3 & -4.1 \\
\hline 2012 & 15.2 & 9.9 & 11.7 & 5.4 & 4.3 & 5.5 & 2.9 & 0.28 & 13.9 & 10.2 \\
\hline 2013 & 6.8 & 1.5 & 3.2 & 2.7 & -1.2 & 6.4 & 3.5 & 0.55 & 10.9 & 25.2 \\
\hline 2014 & 8.5 & 1.3 & 6.1 & 3.7 & -2.3 & 4.9 & 2.7 & 0.55 & 11.9 & 3.4 \\
\hline 2015 & 8.7 & -13.5 & 6.8 & 4.1 & -16.9 & 3.2 & 2.2 & 0.32 & 2.5 & -12.9 \\
\hline 2016 & 4.7 & -1.4 & 2.2 & 1.7 & -3.0 & 0.2 & 3.5 & 0.70 & 0.8 & 6.5 \\
\hline 2017 & 2.7 & 6.0 & 2.0 & -0.7 & 6.8 & 1.0 & -1.6 & 1.50 & 0.7 & 0.5 \\
\hline
\end{tabular}

Source: KAPSARC.

Table A3. Equation specification and parameter estimates - full information maximum likelihood.

Dependent variable:

$\mathrm{dlc}=\Delta \log$ (real economic consumption)

EQ (8):

$\mathrm{dlc}=\theta_{0}+\theta_{1}{ }^{*} \log (\mathrm{ydc}(-1) / \mathrm{ydc}(-2))$

$+\theta_{2}{ }^{*} \log (g d p d e f l / g d p d e f l(-1))$

$+\theta_{3}{ }^{*} \operatorname{rr}(-1)$

$+\gamma^{*} \log (\operatorname{cc}(-1) /(\operatorname{yd}(-1))$ 
Independent variables:

$\theta_{0}:$ constant

$\theta_{1}$ : rate of change of real income

$\theta_{2}$ : rate of change of GDP deflator

$\theta_{3}$ : change in real interest rate $\left[(1+r) /\left(1+p^{\circ}\right)\right]_{-1}$

$\gamma$ : linear error correction term: $\log$ [consumption/ income $]_{-1}$

$\mathrm{EQ}(9)$

$\mathrm{dlc}=\theta_{0}+\theta_{1} * \log (\mathrm{ydc}(-1) / \mathrm{ydc}(-2))$

$+\theta_{2}{ }^{*} \log ($ gdpdefl/gdpdefl(-1))

$+\theta_{3}{ }^{*} \operatorname{rr}(-1)$

$+\theta_{4}{ }^{*}$ oilresratio* $($ wtot(-1)/yd(-1))/(cpi(-1)/100)

$+\gamma_{0}{ }^{*} \log \left(\mathrm{cc}(-1) /\left(\mathrm{yd}(-1)+\gamma_{1}^{*} \operatorname{wtot}(-1)\right)\right.$

$d \ln (c)=+\theta_{1} d \ln (y)+\theta_{2} \pi+\theta_{3} r+\gamma_{0}\left\{\ln (c)-\ln \left[(y)-\gamma_{1}(w)\right]\right\}-{ }_{1}$

Independent variables:

$\theta_{0}:$ constant

$\theta_{1}$ : rate of change of real income

$\theta_{2}$ : rate of change of GDP deflator

$\theta_{3}:$ real interest rate $\left[(1+\mathrm{r}) /\left(1+\mathrm{p}^{\circ}\right)\right]_{-1}$

$\theta_{4}$ : total wealth / income

non-linear error correction term:

$\gamma_{0}{ }^{*} \log \left[\text { consumption/ (income }+\gamma_{1} \text { wealth) }\right]_{-1}$

\section{Equation 8}

Full information maximum likelihood

\begin{tabular}{|c|c|c|c|c|}
\hline \multicolumn{2}{|c|}{ Number of observations $=46$} & \multicolumn{2}{|c|}{ Log likelihood $=65.3681$} & \\
\hline Parameter & Estimate & Standard Error & t-statistic & P-value \\
\hline$\theta_{0}$ & -.065483 & .033789 & -1.93797 & {$[.053]$} \\
\hline$\theta_{1}$ & .412140 & .136309 & 3.02358 & {$[.002]$} \\
\hline$\theta_{2}$ & -.491275 & .075230 & -6.53031 & {$[.000]$} \\
\hline$\theta_{3}$ & -.049126 & $.766908 \mathrm{E}-02$ & -6.40573 & {$[.000]$} \\
\hline$\gamma$ & -.243042 & .078891 & -3.08073 & {$[.002]$} \\
\hline \multicolumn{2}{|c|}{ Mean of dependent variable $=.057357$} & \multicolumn{3}{|c|}{ Standard error of regression $=.060044$} \\
\hline \multicolumn{2}{|c|}{ Standard deviation of dependent variable $=.124974$} & \multicolumn{3}{|c|}{ R-squared $=.790147$} \\
\hline \multicolumn{2}{|c|}{ Sum of squared residuals $=.144213$} & \multicolumn{3}{|c|}{ Adjusted R-squared $=.769162$} \\
\hline \multicolumn{2}{|c|}{ Variance of residuals $=.360533 \mathrm{E}-02$} & \multicolumn{3}{|c|}{ Durbin-Watson $=.986692$} \\
\hline
\end{tabular}

Equation 9

Full information maximum likelihood

Number of observations $=46$

Log likelihood $=52.8798$

\begin{tabular}{l|l|l|l|l}
\hline Parameter & Estimate & Standard Error & t-statistic & P-value \\
\hline$\theta_{0}$ & .058453 & .108826 & .537122 & {$[.591]$} \\
\hline$\theta_{1}$ & .257789 & .225684 & 1.14225 & {$[.253]$} \\
\hline
\end{tabular}




\begin{tabular}{|c|c|c|c|c|}
\hline$\theta_{2}$ & -.335750 & .082085 & -4.09027 & {$[.000]$} \\
\hline$\theta_{3}$ & $-.182962 E-02$ & $.57088 \mathrm{E}-02$ & -.320489 & {$[.749]$} \\
\hline$\theta_{4}$ & -.017574 & $.41568 E-02$ & -4.22762 & {$[.000]$} \\
\hline$\gamma_{0}$ & -.546467 & .121554 & -4.49567 & {$[.000]$} \\
\hline$\gamma_{1}$ & -.068438 & .014114 & -2.43608 & {$[.015]$} \\
\hline \multicolumn{2}{|c|}{ Mean of dependent variable $=.058154$} & \multicolumn{3}{|c|}{ Standard error of regression $=.083246$} \\
\hline \multicolumn{2}{|c|}{ Standard deviation of dependent variable $=.270263$} & \multicolumn{3}{|c|}{ R-squared $=.607476$} \\
\hline \multicolumn{2}{|c|}{ Sum of squared residuals $=.270263$} & \multicolumn{3}{|c|}{ Adjusted R-squared $=.547087$} \\
\hline \multicolumn{2}{|c|}{ Variance of residuals $=.692982 \mathrm{E}-02$} & \multicolumn{3}{|c|}{ Durbin-Watson $=1.87142$} \\
\hline
\end{tabular}

Source: KAPSARC. 


\section{About the Authors}

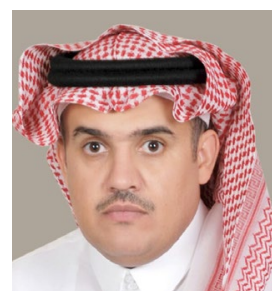

\section{Goblan Al Gathani}

Goblan is a former senior researcher at the Saudi Arabian Monetary Agency (SAMA), Monetary Policy and Financial Stability Department and is now Senior Director at the Royal Court Support Decision Center, Riyadh. He holds a Ph.D. in Economics from the University of Kansas.

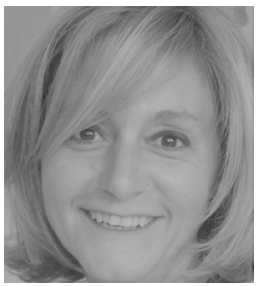

\section{Simona Bigerna}

Simona is Associate Professor of Economics at the University of Perugia, Italy, specializing in energy economics, environmental policy analysis, transport and international economics. She holds a Ph.D. in Economics.

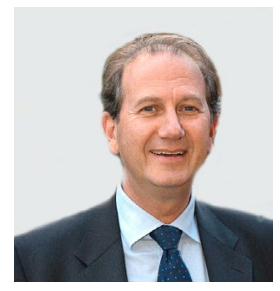

\section{Carlo Andrea Bollino}

Carlo Andrea is a visiting fellow at KAPSARC and Full Professor of Economics at the University of Perugia, Italy, specializing in microeconomic analysis, energy economics and environmental policy. He holds a Ph.D. in Economics from the University of Pennsylvania.

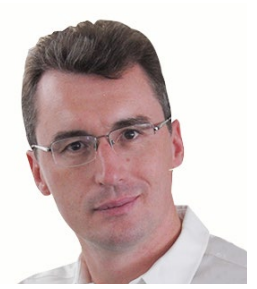

\section{Axel Pierru}

Axel is the interim vice president of research at KAPSARC. He also leads the Energy and Macroeconomics program. He joined KAPSARC in 2011 after 15 years at IFP Energies Nouvelles in France, Axel holds a Ph.D. in Economics from the PantheonSorbonne University in Paris.

\section{About the Project}

This research is part of a joint project between the Saudi Arabian Monetary Authority (SAMA) and KAPSARC to study the macroeconomic structure of the Saudi economy.

The life cycle consumption model has been estimated for the Saudi Arabian economy, including both income and wealth effects. This modeling exercise showed some relevant implications for macro policy design. 
INAPSARC

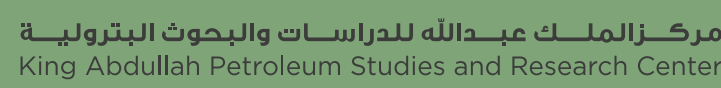

www.kapsarc.org 